\title{
Informed grounded theory
}

\author{
Robert Thornberg
}

\section{Linköping University Post Print}

N.B.: When citing this work, cite the original article.

This is an electronic version of an article published in:

Robert Thornberg, Informed grounded theory, 2012, Scandinavian Journal of Educational Research, (56), 3, 243-259.

Scandinavian Journal of Educational Research is available online at informaworld ${ }^{\mathrm{TM}}$ :

http://dx.doi.org/10.1080/00313831.2011.581686

Copyright: Taylor \& Francis (Routledge) http://www.routledge.com/

Postprint available at: Linköping University Electronic Press http://urn.kb.se/resolve?urn=urn:nbn:se:liu:diva-69969 


\title{
Informed Grounded Theory
}

\author{
Robert Thornberg \\ Linköping University, Sweden
}

\begin{abstract}
There is a widespread idea that in grounded theory (GT) research, the researcher has to delay the literature review until the end of the analysis to avoid contamination - a dictum that might turn educational researchers away from GT. Nevertheless, in this article the author (a) problematizes the dictum of delaying a literature review in classic grounded theory, (b) presents arguments for using extant literature in the substantive field within a constructivist grounded theory, and (c) suggests data sensitizing principles in using literature, which are: theoretical agnosticism, theoretical pluralism, theoretical sampling of literature, staying grounded, theoretical playfulness, memoing extant knowledge associations, and constant reflexivity.
\end{abstract}

Keywords: grounded theory, literature, qualitative analysis, constructivism, theoretical sensitivity

\section{Informed Grounded Theory}

The grounded theory (GT) approach is a widely cited and frequently used approach in a wide range of disciplines and subject areas, including the field of qualitative research in education (for examples of recently publicized GT studies in educational research, see Cherubini, Niemczyk, Hodson, \& McGean, 2010; Drugli, Clifford, \& Larsson, 2008; Givon \& Court, 2010; Leino, 2006; Smart \& Brent, 2010). My main concern in this article is the issue of reviewing literature in GT. Its original ideas of pure induction and not taking advantage of and using literature when collecting and analyzing data could easily be criticized, which in turn might lead to a rejection of GT among educational researchers of today (cf. Thomas \& James, 2006). In this article, I problematize the original idea of pure induction and the classic dictum of delaying a literature review create, and I present arguments for using extant literature in the substantive field, and finally I suggest data-sensitizing principles when using literature. What I call informed GT is about adding literature review strategies to the GT research approach.

\section{The Classic Dictum of Delaying Literature Review}

GT was originally developed by Glaser and Strauss (1967) as a new methodology defined as "the discovery of theory from data" (p. 1) and was a reaction at the same time to the dominant hypothetico-deductive use of "grand theories" in the social research of the 1960s. In contrast to only verifying theories by quantitative methods, they offered a set of qualitative methods for 
generating inductive theories from data. After their collaboration, the two originators took different career paths and by the early1990s, two distinct versions of GT had emerged - Glaserian GT (Glaser, 1978, 1992, 1998) and Straussian GT, which in large part Strauss developed in collaboration with Corbin (Strauss, 1987; Strauss \& Corbin, 1990, 1998). A third version called constructivist GT was developed by Charmaz (2000, 2006, 2008, 2009) and others (Bryant, 2002; Mills, Bonner, \& Francis, 2006a; Mills, Bonner, \& Francis, 2006b). Other examples of later developments in GT methodology are Dey's (1999) version with a elaborated view on categorization, process, causality, and structure/agency in GT, and Clarke's (2005) postmodern version called situational analysis.

The original work of Glaser and Strauss (1967) and Glaser's (1978, 1998, 2001, 2005) further development of GT (labeled "classic" GT by Glaser and his advocates) argue for delaying the literature review in researcher's substantive area of inquiry until the analysis is nearly completed. They contend that delaying the literature review aids the researcher to generate a theory that fits with and is well-grounded in the empirical world. The main reasons behind their dictum are: (a) to keep the researcher as free and open as possible to discover, and (b) to avoid contamination, e.g. forcing data into pre-existing concepts which distort or do not fit with data or have no relevance to the substantive area. As Heath (2006) puts it, "the result would be a constructed theory, supporting what was already known, rather than emergent theory providing new insights" (p. 520). Further- more, Glaser (1998) argues that the answer concerning which literature is relevant is unknown prior to the study and remains so until the end of the analysis. Only then do we have enough knowledge about our own study to make an adequate literature search and weave it into the GT. In addition, by delaying a literature review until the end of the study, time is saved from reading wrong literature.

\section{Problems with Delaying Literature Review}

The dictum of not reading literature in the substantive area until the end of the analysis in classic GT, is however problematic for several reasons. First, if this dictum is taken seriously, it makes it impossible for researchers to conduct studies in their own areas of expertise which appears odd and counter-intuitive. According to Bruce (2007), a "responsible" researcher has to admit his or her theoretical understandings from the outset of the study. He or she cannot "unlearn" what is already known (Schreiber, 2001). Alternatively, the dictum might force the informed researcher to pretend to be a "theoretical virgin" (Clarke 2005), which in turn might mask unreflective, preconceptive forcing as well.

Second, the dictum can easily be used as an excuse for lazy ignorance of the literature (Silverman, 2000; Suddaby, 2006), which may lead to the belief and accusation that such research is "easy" and "atheoretical" (Morse, 1994). Third, if researchers avoid reading literature in the field but at the same time read literature in other unrelated fields, in accordance with Glaser's (1978) recommendation for enhancing theoretical sensitivity (see below), and then, at the end of the analysis, begin to review the field literature, they will soon drive themselves into a corner during their research career because of the accumulative reduction of possible research fields, which they still have not read literature about. And if the researchers want to do more studies in the same field, preconceptions are indeed inevitable. 
Fourth, as several grounded theorists have noticed (e.g. Bruce, 2007; Clarke, 2005; Dunne, 2011; Hallberg, 2010; McCallin, 2006; Schreiber, 2001), before the research begins, the researcher has to prepare proposals for the purpose of receiving funding for the project and undergo an ethical review. Hence, for pragmatic and strategic reasons, the researcher has to begin theorizing and reading literature before starting any data collection and analysis, because, in these review processes, an overview or summary of related literature is normally required to acquire approvals.

Fifth, ignoring established theories and research findings implies a loss of knowledge. "A dwarf standing on the shoulders of a giant may see further than the giant himself" (Burton, 2007, p. 27; also see Stern, 2007). The researchers have to recognize that what might appear to be a totally new idea to them in terms of an "innovative breakthrough" in their research might simple be a reflection of their own ignorance of the literature (Lempert, 2007). Instead of running the risk of reinventing the wheel, missing well-known aspects, and coming up with trivial products or repeating others' mistakes, the researchers should take advantage of the pre-existing body of related literature to see further. There are, for instance, GT researchers who witness how literature in the field helped them to draw their attention to details in data, and then being able to go beyond the literature in their analysis (e.g. Bowen, 2006; Dunne, 2011; Stern, 2007). An early and on-going literature review reveals how the phenomenon has been investigated to date (Dunne, 2011), helps the researcher to be aware of and avoid earlier conceptual and methodological pitfalls (Dunne, 2011; McGhee, Marland \& Atkinson, 2007), and stimulates theoretical sensitivity (Bryant, 2009; Dunne, 2011; Strauss, 1987; Strauss \& Corbin, 1990, 1998). In contrast to Glaser's position, Strauss and Corbin $(1990,1998)$ argue that literature can be used more actively in GT research as long as the researcher does not allow it to block creativity and get in the way of discovery. According to them, familiarity with relevant literature can enhance sensitivity to subtle nuances in data, provide a source of concepts for making comparisons to data, stimulate questions during the analysis process (e.g., when there is a discrepancy between a researcher's data and the findings reported in the literature), and suggest areas for theoretical sampling. Using the literature enriches the analysis, while simultaneously encouraging the researcher to take a critical stance and challenge "emergent" concepts and ideas. Moreover, it can help the researcher to formulate relevant research questions and make constant comparisons between data and literature to elaborate, revise or criticize pre-existing knowledge and extant theories.

Sixth, the dictum of not reading literature early on in the research process as a solution to the fear of contamination and forcing is an extreme position that underestimates researchers' ability to reflect upon the links between extant theories and their gathering and analysis of data (Dunne, 2011), and to appreciate extant theories and concepts without imposing them on the data (Urquhart, 2007). Dunne states;

Indeed, if the fundamental concern of Glaser is the threat of external ideas impinging upon the research and distracting focus away from the raw data, then perhaps there is a way to monitor and counteract this threat which is less extreme than the initial abstinence from literature which he prescribes. After all, it would be both unfortunate and unconstructive to sacrifice the numerous advantages derived from conducting an early literature review based on a concern about what impact extant ideas might have on the researcher (Dunne, 2011, p. 117). 


\section{Problems of Pure Induction in GT}

The very idea of a researcher who collects and analyses theory-free data without any prior theoretical knowledge and preconceptions, has been strongly criticized by scientist philosophers (e.g., Chalmers, 1999; Hanson, 1965; Thayer-Bacon, 1996, 2003) and later grounded theorists (e.g., Bryant, 2009; Charmaz, 2006; Clarke, 2005; Dey, 1999; Dunne, 2011; Kelle, 2007; Lempert, 2007; Schreiber 2001). "This tabula rasa approach is dangerous because it leaves the analyst prone to all manner of prejudices and preconceptions, which are no less powerful for remaining subliminal. It is better to make ideas and values explicit rather than leaving them implicit and pretending that they are not there" (Dey, 1993, p. 229). There is no neutral position, no objective God's eye view of the world (Thayer-Bacon, 2003). Such naïve empiricism fails to recognize the embeddedness of the researcher within an historical, ideological and socio-cultural context.

Researchers who investigate a different form of life always bring them their own lenses and conceptual networks. They cannot drop them, for in this case they would not be able to perceive, observe and describe meaningful events any longer - confronted with chaotic, meaningless and fragmented phenomena they would have to give up their scientific endeavour (Kelle, 1995, p. 38).

Empirical observation could never be totally free from theoretical influence because seeing is already a "theory-laden" undertaking. Observation of a phenomenon is inevitably shaped by prior knowledge of the phenomenon (Hanson, 1965; Kelle, 1995, 2005, 2007). This makes troubles for the position of pure induction. As Bryant (2009) puts it, once this issue of data has been raised, we can no longer retreat behind the claim that "it's all there in the data", which is the basic claim in pure induction.

In addition, as Charmaz (2006) noted, Glaser's position is ambiguous. It is neither entirely inductive nor free from influence from extant theories and concepts. Glaser (1978, 1998, 2005) strongly advocates researchers to avoid being contaminated by preconceived concepts and ideas. However, at the same time Glaser $(1978,1998,2005)$ argues that researchers should possess prior knowledge and read literature in other substantive areas, unrelated to the actual research project, for the purpose of enhancing their theoretical sensitivity by knowing many theoretical codes, e.g. underlying logics that could be found in pre- existing theories. These are used in GT research in what is called theoretical coding as analytical tools in order to conceptualize how categories and codes generated from data may relate to each other as hypotheses to be integrated into a theory. As a guide, Glaser $(1978,1998,2005)$ has organized a lot of theoretical codes in a typology of coding families, such as the "Six C"' (Causes, Contexts, Contingencies, Consequences, Co-variance, and Conditions), Process (phases, progressions, passages, transitions, careers, trajectories, cycling etc.), Type Family (type, styles, classes, genre etc.), Identity-Self Family (self- image, self-concept, self-worth, self-evaluation, identity, transformations of self etc.), Cutting Point Family (boundary, cutting point, turning point, breaking point, deviance etc.), Paired Opposite Family (ingroup - outgroup, in - out, manifest - latent, explicit - implicit, overt-covert, informal-formal etc.), and Cultural Family (social norms, social values, social beliefs etc.). However, theoretical codes must, according to Glaser, fit with data and earn their way into a GT analysis ("emergent fit"). But still, theoretical codes or coding families are extant concepts and ideas, which are imported into the analysis, and therefore conflict with the logic of pure induction. 


\section{The Abductive Turn and its Relation to Using Literature}

Later grounded theorists have argued that abductive reasoning is an essential component of GT methodology (e.g., Bryant, 2009; Bryant \& Charmaz, 2007; Dey, 2004; Kelle, 2005; Locke, 2007; Reichertz, 2010; Richardson \& Kramer, 2006). The general idea of abduction is to select or invent a hypothesis that explains a particular segment or set of data better than any other candidate hypotheses (Douven, 2011a, b), "where the adoption of the hypothesis is not as being true or verified or confirmed, but as being a worthy candidate for further investigation" (Douven, 2011b). It is, according to Atkinson, Coffey and Delamont (2003), "a way of capturing the dialectical shuttling between the domain of observations and the domain of ideas" (p. 149). Schurz (2008) gives us this description of abduction:

Different from the situation of induction, in abduction problems we are confronted with thousands of possible explanatory conjectures (or conclusions) - everyone in the village might be the murderer. The essential function of abduction is their role as search strategies which tell us which explanatory conjecture we should set out first to further inquiry ... or more generally, which suggest us a short and most promising (though not necessarily successful) path through the exponentially explosive search space of possible explanatory reasons (Schurz, 2008, p. 203-204).

The American pragmatist philosopher Charles S. Pierce (1958) first introduced the concept of abduction as something between deduction and induction, referring to a selective and creative process in which the researcher carefully investigates how far empirical "facts" (or data) agree with theory or hypothesis and how far they call for modifications of it. It is about discovering new concepts, ideas or explanations by finding surprising events, which cannot be routinely explained by pre-existing knowledge. Thus, by abduction, the researcher goes beyond data as well as the pre-existing theory or theories. It is an innovative process because every new insight is a result of modifying and elaborating prior knowledge or putting old ideas together in new ways as the researcher explores and tries to explain the new data. Abduction is hence the source of scientific creativity (Anderson, 1987).

Like the fictional detective Sherlock Holmes, a researcher who uses abductive reasoning constantly moves back and forward between data and pre-existing knowledge or theories, and makes comparisons and interpretations in the searching for patterns and best possible explanations (cf. Bryant, 2009; Carson, 2009; Truzzi, 1976). The researcher tries to be open and sensitive to the data, without rejecting pre-existing theoretical concepts and constructions. Theories are used, not to mechanically derive a hypothesis to test (as in deduction), but as a source of inspiration, seeing, and interpretation in order to detect patterns (Alvesson \& Sköldberg, 2008).

According to Schurz (2008), abduction consists of different strategies, such as backward reasoning (including all sorts of causal interpretations of traces), probabilistic evaluation of explanations and eliminations of implausible explanations, testing abducted hypotheses by further empirical investigations, introducing new concepts or theoretical models, and analogical reasoning based on conceptual abstraction, i.e., finding the theoretical essential features of the source structure which can be generalized to other areas or domains (for further readings on different understand- 
ings of abduction, see Douven, 2011a; Schurz, 2008).

My key argument here is that the grounded theorist has to accept the impossibility of pure induction and at the same time recognize the analytical power of the constant interplay between induction (in which he or she is never tabula rasa) and abduction. Although most philosophers agree that abduction, in some form or other, is frequently employed in everyday and in scientific reasoning as well (Douven, 2011a), Kelle (1995) stresses that the ability to draw good abductive inferences is dependent on the researcher's previous knowledge, rejection of dogmatic beliefs and development of open-mindedness.

\section{Epistemology, Constructivist GT, and Using Literature}

Even if the original GT and Glaser's developed version of GT has been criticized as positivistic with a naïve realist concept of data and a reliance on pure induction (e.g., Bryant, 2009; Charmaz, 2000, 2006; Clarke, 2005; Kelle, 2007; Olesen, 2007), the later Glaser (2003, 2005) claims that his classic GT is not positivistic and has actually no epistemology at all. "The quest for an ontology and epistemology for justifying GT is not necessary" (Glaser, 2005, p. 145). Glaser (2005) dismisses epistemological positioning as "an epistemological, rhetorical wrestle that gets wordy and goes nowhere ... Epistemological discussions are of no potential help to the actual doing of research" (p. 2). For him, a certain epistemological framework as a starting point and a base for research is wrong - it functions as a "pet" code, which will result in preconceived forcing and biases. Glaser argues that the researcher just has to have trust in the emergence of concepts and theory by collecting and analyzing the data in accordance with his prescription of GT. In addition, Glaser (2003) claims that "data is rendered objective to a high degree by most research methods and GT in particular by looking at many cases on the same phenomenon, when joint collecting and coding data, to correct for bias and make the data objective" (p. 173). When considering his trust in the ability of the data to "speak for itself", his basic assumption that the researcher can and has to be unbiased (e.g., Glaser, 1992, 1998) and his idea that epistemological positioning is meaningless in GT research (Glaser, 2005), Glaser's position is, at least, very similar to the naïve empiricism that characterizes positivism.

At the same time, there are other parts of Glaser's writings that are more similar to ideas from pragmatism (e.g., fit, workability, relevance and modifiability as his four criteria of judging and doing GT, and his claim that the focus should be on the main concern of the people in the substantive area and to generate a GT to explain how they resolve their main concern, and his idea of theoretical coding). Furthermore, although Glaser's rejection of epistemology might be interpreted as a positivist influence, it could also be argued that it has a resemblance with Rorty's $(1979,1998)$ neopragmatism. We cannot be sure however, because Glaser makes no citations when he argues for his anti-philosophical stance, probably as a result of his basic assumption that data "can speak for itself", his trust in the unbiased tabula rasa researcher, and his disinterest in epistemology.

In contrast to classic GT, a later version of GT called constructivist GT, rooted in pragmatism and relativist epistemology, assumes that neither data nor theories are discovered, but are constructed by the researcher as a result of his or her interactions with the field and its participants 
(Charmaz, 2006, 2008, 2009; Mills et al., 2006b; Thornberg \& Charmaz, in press). Data are coconstructed by researcher and participants, and colored by the researcher's perspectives, values, privileges, positions, interactions, and geographical locations (Charmaz, 2008, 2009; Mills et al., 2006a). This position takes a middle ground between the realist and postmodernist positions (Bryant \& Charmaz, 2007; Charmaz, 1995) by assuming an "obdurate reality" (cf. Blumer, 1969) at the same time as it assumes multiple realities and multiple perspectives on these realities (Charmaz, 2008, 2009). Social realities are mutually constructed through interaction and are therefore subject to redefinition, and are somewhat indeterminate (for a further discussion, see Bryant \& Charmaz, 2007; Charmaz, 2006, 2008, 2009). As a logical consequence, constructivist grounded theorists "advocate recognizing prior knowledge and theoretical preconceptions and subjecting them to rigorous scrutiny" (Charmaz, 2008, p. 402) rather than being tabula rasa.

\section{Informed Grounded Theory}

If researchers reject a naïve empiricism as well as theoretical forcing, then they do not dismiss extant theoretical and research literature nor apply it mechanically to empirical cases. Instead these researchers use the literature as a possible source of inspiration, ideas, "aha!" experiences, creative associations, critical reflections, and multiple lenses, very much in line with the logic of abduction. Kelle $(1995,2005)$ recognizes that pre-existing theories and research findings can be used as heuristic tools, i.e. using extant concepts, theories and ideas as "lenses" and tools that help the researcher to focus the attention on certain phenomena, aspects or nuances as well as imaginarily see beyond data.

What I call informed grounded theory refers to a product of a research process as well as to the research process itself, in which both the process and the product have been thoroughly grounded in data by GT methods while being informed by existing research literature and theoretical frameworks. There is, as Dey (1993) highlights, "a difference between an open mind and empty head" (p. 63). In contrast to the classic GT tradition, but in accordance with the constructivist GT tradition, an informed grounded theorist sees the advantage of using pre-existing theories and research findings in the substantive field in a sensitive, creative and flexible way instead of seeing them as obstacles and threats. Informed GT has its roots in constructivist GT and the pragmatist idea of abduction, and hence fits in very well with constructivist GT. Yet its sensitizing principles in how to use literature (see below) can also work in tandem with Glaser's as well as Strauss and Corbin's versions of GT as long as the researcher rejects pure induction and the dictum of delaying literature, uses the logic of abduction during the whole research process, and recognizes his or her embeddedness within an historical, ideological and socio-cultural context, and hence that data always are social constructions and not exact pictures of the reality. Informed GT can also be combined with Dey's (1999), Clarke's (2005) and Goldkuhl and Cronholm's (2010) versions of GT, especially since these approaches so strongly reject the idea of tabula rasa position and assume as well as recognizing the value of researchers' perspectives and prior knowledge. In their approach called multi-GT, Goldkuhl and Cronholm (2010) actually argue that research has to be grounded in data and literature as well (also see Lind \& Goldkuhl, 2006). Thus, informed GT is not a new version of GT, but only adds literature review strategies to the already existing family of GT. 


\section{Data Sensitizing Principles in Using Literature}

Informed GT is not about forcing data into pre-existing concepts and theories nor replacing constant comparison and systematic coding with prejudiced and insensitive theoretical interpretations of data. Therefore I suggest data sensitizing principles in using literature by organizing and presenting arguments from the field of qualitative research and philosophy of science as well as my own arguments.

\section{Theoretical Agnosticism}

It is essential for researchers who conduct GT research, Timmermans and Tavory (2007) argue, that they do not subscribe to any of the theories they might know or have reviewed before or during data collection and analysis (cf. Glaser's concept of "pet code"), and are sensitive to different theoretical positions, the cracks between the theories, and the spaces in the literature. Theoretical agnosticism (Henwood \& Pidgeon, 2003, p. 138) means that the researchers should take a critical stance toward pre-existing theories and research findings throughout the research project (Charmaz, 2006). Hence, working cumulative, i.e. relating to or building on earlier work, should not be confused with being uncritical and taking pre-existing theories for granted. The critical dimension is essential in cumulativeness: distinguish between what is usable and what should be refuted (Goldkuhl \& Cronholm, 2010).

The trick in theoretical agnosticism is to treat all extant theories and concepts that one already knows or might encounter during the pre-study or on-going literature review as provisional, disputable and modifiable conceptual proposals. As consistent with the pragmatist emphasis on fallibilism, any ideas (including those the researcher him- or herself construct) must be open to doubt (see Bryant, 2009). Grounded theorists must have an ability to think critically, question underlying assumptions and assume a cautious and skeptical attitude to the content of the literature throughout the study (McCallin, 2006). As Martin (2006) argues, the grounded theorists have to be aware of the limitations of the pre-existing literature, remain non-committal, and "boldly go where nobody in their discipline has gone before" (p. 50). Approaching extant theories and concepts in this way might help the researcher to draw his or her attention to potentially relevant or important features of data and provide a general sense of reference as well as guidelines in specific settings without any forcing. The literature review should therefore be seen as an open, critical and pluralistic conversation between the researcher, the literature, the data and the "emerging" body of concepts and ideas.

\section{Theoretical Pluralism}

One of the strategies that Kelle (2005) suggests to cope with the risk of forcing extant concepts to data and neglecting other extant concepts that would suit the data even better is the use of different and even competing theoretical perspectives. Theoretical pluralism provides the researcher with flexible choices among different extant concepts and ideas. "Entertaining different explana- 
tions is a way of keeping an open mind" (Dey, 1993, p. 229). Different theoretical perspectives to data should keep the researcher's eyes open to all kind of observations and aspects, not confining or blinding his or her view. Furthermore, to consider and compare different pre-existing theories helps the researcher to take a critical stance toward each of them and thus remain theoretically agnostic during the analysis.

Theoretical pluralism, as I use it, has nothing to do with vulgar relativism but is associated with what Thayer-Bacon $(1996,2003)$ calls qualified relativism, rooted in pragmatism. This perspective rejects the idea that "anything goes" but assumes that all inquiries are influenced by philosophical assumptions which are socio-culturally bound, and stresses that the construction of knowledge is social, interactive, ongoing, flexible, and tentative. Pluralism offers the means for adjusting for each theoretical position's limitations, and for correcting, improving or revising its standards and arguments.

Thayer-Bacon (1996) uses as a metaphor the well-known poem of six blind men who explore an elephant from different positions and describe it as like a rope, a tree, a fan, a snake, a wall, and a spear on the basis of the part of the elephant that each man touched. While a vulgar relativist claims that it does not matter what one's perspective is, in relation to the elephant, for all perspectives are right ("true"), a qualified relativist (a) insists on the need for pluralism, i.e. a conversation between different perspectives, in relation to the elephant, to reach a more qualified understanding, (b) accepts fallibilism, i.e. that we can never attain knowledge that is certain because we are fallible, limited, and contextual beings, and (c) claims that knowledge is a social process of knowing that is continually in need for re/adjustment, correction, and re/construction.

Inviting theoretical pluralism during the analysis is a way of initiating a critical, creative and sensitive conversation between different and even conflicting theoretical perspectives to explore and interpret data and at the same time avoiding forcing what Glaser calls a "pet code" on to data, i.e. avoiding the position of one blind man in the poem above. The researcher also investigates and reflects upon underlying philosophical assumptions of external theories and concepts in order to better understand them. However, in line pragmatism and qualified relativist epistemology, the use of external theories and concepts are not determined by their epistemological roots or underlying philosophical assumptions per se, but by their usefulness in the actual study, i.e. by the way they fit and work with the data, codes, concepts and "emerging" theory that the researcher has generated or is going to generate by GT methods. Moreover, in accordance with the logic of abduction, the researcher is not restricted to theoretical orthodoxy but is prone to modify or elaborate extant concepts if he or she finds the need to do so in order to achieve a better fit and workability.

Nevertheless, the researcher has to be careful not to be too ambitious in developing a repertoire of theories so it causes too much reading and literature overload in a way that draws his or her time and attention too much away from data gathering and analysis. To avoid this trap, I suggest using the principle of theoretical sampling applied to the ongoing literature search as well as the principle of staying grounded, which are discussed below. The principle of theoretical pluralism is especially suitable for researchers who already possess a great amount of theoretical knowledge in the substantive field as well as in other associated or relevant fields. 


\section{Theoretical Sampling of Literature}

Glaser (1998) argues that the answer to which literature is relevant is unknown prior to the study and remains so until the main concern of the participants, the core concept, and the GT emerge. Furthermore, by delaying a literature review until the end of the study, time is saved from reading wrong literature, Glaser (1998) argues. Nevertheless, at least two objections can be raised against his argument. First, I do not agree with Glaser that the question of which literature is relevant is entirely unknown prior the study. A substantive field is in fact identified even if it is unfocused and fuzzy in the beginning (e.g. disciplining in school, negotiations in classrooms, teacher collaboration, or school bullying). This starting point can be related to what ethnographers call "foreshadowed problems", which are open for further elaboration, clarification and reformulation during fieldwork and analysis (Hammersley \& Atkinson, 2007). Thus, instead of delaying the literature review, the researcher should investigate the prior knowledge in the substantive field to enhance his or her theoretical sensitivity as well as the potential of the study to relate and contribute to this pre-existing knowledge.

Second, instead of being snowed under with too much literature and wasting too much time on "wrong" literature, as Glaser puts it, the researcher should simply apply the logic of theoretical sampling in relation to the ongoing literature search during the study (and after an initial broad literature review before the study). Glaser and Strauss (1967) define theoretical sampling as "the process of data collection for generating theory whereby the analyst jointly collects, codes and analyses his data and then decides what data to collect next and where to find them, in order to develop his theory as it emerges" (p. 45). By applying this principle to the ongoing literature review, the researcher searches and reads literature guided by the codes, concepts, questions, and ideas that he or she develops during data collection and analysis. It is a highly interactive process in which the researcher's coding and questions take him or her to some of the literature, which in turn sends him or her back to the empirical field and to his or her tentative codes and concepts with new lenses and questions, and so on.

An ongoing literature review, based on theoretical sampling, can help the researcher to be more sensitive to data, to elaborate his or her constructed themes, concepts and ideas, and to offer new insights into questions and issues. Instead of ignoring the literature, the researcher uses it for comparison with "emerging" codes and concepts (Morse, 2001). When the researcher has generated a core category (Glaser, 1978, 1998, 2001) or a set of focused codes (Charmaz, 2006), this construction will guide the further theoretical sampling of literature. Moreover, there are various types of literature, and it is possible that the researcher finds literature with a more empirical description content more helpful in the earlier stages of the research project, and literature with a more abstract and conceptualized content as more useful in the later stages. In addition, the GT concept of theoretical saturation, defined by Charmaz (2006), as the point "when gathering fresh data no longer sparks new theoretical insights, nor reveals new properties of your core theoretical categories" (p. 113), is also useful when deciding to stop doing theoretical sampling of literature. Thus, the researcher keep sampling until his or her categories are saturated and his or her grounded theory is complete and without "holes" or hypothetical links that are not grounded (Thornberg \& Charmaz, in press). Nevertheless, judging saturation is always tricky and thus risks foreclosing analytic possibilities and constructing superficial analyses (Charmaz, 2006). 


\section{Staying Grounded}

Hickey (1997) experienced that his pre-study literature review led him in the wrong direction by giving him assumptions that mismatched with data. Fortunately, he was sensitive to data and did not treat prior knowledge as sacred truths. I emphasize the principle of "empirical figure and literature background". The researcher has to remember that the main focus is on data, not on literature, and that every code, concept or theoretical idea he or she constructs must be grounded in data by GT methods. Prior knowledge must never be used as an excuse for a poor analysis of data. It can never replace the work of constant comparison between data and data, data and codes, codes and codes, data and concepts, concepts and concepts, and so on. As Hallberg (2010) puts it, "One way to stay open and do good GT-studies is to maintain theoretical sensitivity through constant comparisons ... a and continuous memo writing" (p. 1). Even if I acknowledge and take advantage of my prior knowledge in the substantive field as well as my more general knowledge of theories and theoretical coding families, still during data collection and analysis I constantly switch between the active use of prior knowledge as analytical tools and the mentally striving to put my prior knowledge aside in my exploration of data even if I can never of course erase my prior knowledge (cf., Dey 1993).

I have found some of Strauss and Corbin's (1998) advice to be a good help in this interplay: (a) think comparatively, (b) obtain multiple viewpoints of an event, (c) gather data on the same event or phenomenon in different ways, (d) occasionally check out assumptions and hypotheses against incoming data, (e) periodically step back and ask, "What is going on there?" and "Does what I think I see fit the reality of the data?", and (f) maintain an attitude of skepticism and regard all categories, hypotheses and theoretical explanations that I construct or use as provisional (see pp. 43-46). Extant theoretical concepts and ideas from literature in the substantive field have to earn their way into a GT in the same way as Glaser $(1978,1998,2005)$ argues that theoretical codes must earn their way, i.e. by coding, constant comparison, theoretical sampling, memo writing, and memo sorting. They have to make sense to and fit with data and substantive codes and concepts.

\section{Theoretical Playfulness}

Qualitative inquiry draws on critical thinking as well as creative thinking. Critical thinkers apply a systematic and disciplined intellectual work with rigorous attention to detail and "a critical perspective in questioning emergent patterns even while bringing evidence to bear in support of them" (Patton, 2002, p. 513). Nevertheless, they tend not to be very creative. Therefore, in qualitative research, critical thinking has to be combined with creative thinking to generate new possibilities and creative connection-making (Patton, 2002), which is essential in abductive reasoning (e.g. Anderson, 1987). Associative and creative ways of thinking allow the researcher to move beyond a descriptive cataloguing of data to theorizing imaginatively. Imaginative freeplaying thinking helps the researcher to treat it as an indicator of something else, and to imagine what that something else might be (Locke, 2007).

Creativity is also a vital component of the grounded theory method. Its procedures force the researcher to break through assumptions and to create new order out of the 
old. Creativity manifests itself in the ability of the researcher to aptly name categories; and also to let the mind wander and make the free associations that are necessary for generating stimulating questions and for coming up with a comparisons that lead to discovery (Strauss \& Corbin, 1990, p. 27).

Charmaz (2006) argues that constructing theory is not a mechanical process, and refers inter alia to what she calls theoretical playfulness. "Whimsy and wonder can lead you to see the novel in the mundane. Openness to the unexpected expands your view of studied life and subsequently of theoretical possibilities" (p. 136). I suggest that researchers expand Charmaz notion of theoretical playfulness by also inviting extant theories and concepts in this playfulness, i.e. playing with them in new, innovative, creative and unorthodox ways during the constant comparison process. Theoretical agnosticism as well as theoretical pluralism makes room for playfulness of extant theories and concepts, which in turn promotes flexibility, fresh ideas and new possibilities as well as counteracting uncreative, forcing, and mechanically applications of pre-existing knowledge. A way of enhancing the ability of playing with and creatively using theories is, I think, to "read for ideas" (Glaser, 1978), for penetrating the patterns of latent logics, and figuring out the theoretical codes and models used in other's writings (Glaser, 1998) - not only in literature unrelated to the field, as Glaser suggests, but also in literature in the field of study. The risk of merely recycling extant theories is obvious if literature in the substantive area is used as a mechanical application (cf. Heath, 2006). However, by abductive reasoning, theoretical playfulness and staying grounded, the researcher will go beyond the "box" of extant theories, and act as the dwarf who stands on the giants' shoulders to see further than the giants. Consequently, the informed GT constructed by the researcher might extend and elaborate as well as challenge and revise pre-existing concepts and theories.

\section{Memoing Extant Knowledge Associations}

According to Glaser (2004), memos are "theoretical notes about the data and the conceptual connections between categories" (p. 61). They are a documentation of the researcher's thinking process and theorizing from data. They transform field-note descriptions or other data documentations into theoretical accounts (Montgomery \& Bailey, 2007). By memo writing (memoing), the researcher develops ideas, conceptualizes data and makes analytical conversations with him- or herself about the data and the research. This is a sort of self-conversation in which new ideas and insights arise during the act of writing (Charmaz, 2006). I agree with Glaser (2004) that researchers in their memoing should "develop ideas and categories with complete freedom into a memo fund" (p. 63). By using the principles I suggest, a preconceived approach will not conflict with the freedom of memoing, that Glaser (2004) warns about, because preexisting concepts are not used as forcing concepts, only as flexible, modifiable and sensitive ideas, creative associations, and heuristic tools. Lempert (2007) reports how she for example uses other researchers' ideas and theoretical insights to inform and sensitize herself to potential patterns in data during her memo writing. By writing them down and documenting how one associates them with data, substantive codes and memos, the researcher facilitates the use of them in the processes of constant comparison, coding, theoretical sampling, and construction of GT. 


\section{Constant Reflexivity}

In qualitative research, the researcher uses him- or herself as a main instrument in data collection and analysis. Therefore, reflexivity is viewed as highly important among many later grounded theorists (e.g., Charmaz, 2006, 2008; Dey 2007; Dunne, 2011; McGhee et al., 2007; Mills et al., 2006a; Mruck \& Mey, 2007). "What is needed is for the researcher to recognize her or his own assumptions and beliefs, make them explicit, and use GT techniques to work beyond them throughout the analysis" (Schreiber, 2001, p. 60). By acknowledging his or her prior knowledge and theoretical understanding, the researcher also acknowledges the need for constant reflexivity instead of denying prior knowledge, perspectives and privileges, and pretending to be without preconceptions and theoretical influences. The researcher has to reflect on his or her underlying assumptions and the analytical lenses through which he or she gazes at the data (Mills et al., 2006a).

Furthermore, personal writing, either as memoing or as a separate personal journal or research diary, could be used as a "self-monitoring tool" (cf., Mruck \& Mey, 2007) in which the researcher reflects on and becomes aware of how his or her own concepts are constructed and monitors how the literature, previous research and theoretical constructions are used. Memoing is a significant tool for reflexivity (Dunne, 2011). "Reflective memo writing makes clear the multiplicity of influences in the reconstruction of theory" (Mills et al., 2006a). Constant reflexivity together with reflective memoing help the researcher to explicitly compare and contrast multiple theories and extant concepts with each other and with data and substantive concepts, to uphold a theoretical agnosticism, to stay grounded, and to document all these ongoing processes for further analysis and conceptualization, especially when comparing memos with memos, and writing memos about memos.

\section{Conclusions}

GT still has much to contribute within the field of educational research. GT varies across different researchers and has also evolved over the years and continues to develop beyond the original developers. What I call informed GT is an elaboration of the constructivist GT and a consequence of its epistemology and view of the researcher's position. Nevertheless, from a pragmatist point of view, this approach might also be applied within other versions of GT as long as the researcher rejects naïve empiricism, the impossible position of pure induction, and Glaser's dictum of delaying the literature review. In an informed GT approach, the researcher takes the advantage of preexisting theories and research findings in the substantive field in a sensitive, creative, and flexible way. These are not uncritically adopted in the analysis but are judged in terms of their relevance, fit, and utility. The informed grounded theorists do not use the literature as forcing applications or deductions, but are guided by a set of data sensitizing principles.

While I directly address GT here, these principles address more broadly the analytical relationship between literature and data in an array of qualitative research approaches. When conducting a study, the principles above help the researchers to (a) be aware of their theoretical knowledge and assumptions, (b) take advantage of pre-existing research and theories to enhance their theoretical sensitivity, (c) remain free, open and data sensitive, and (d) avoid forcing pre-existing 
theories, concepts or assumptions as "pet codes" or non-fitting irrelevant codes into their analysis. By being informed, the researcher not only situates his or her study and its product in the current knowledge base of the field but will also contribute to it by extending, challenging, refining, or revising it.

\section{References}

Alvesson, M., \& Sköldberg, K. (2008). Tolkning och reflektion: Vetenskapsteori och kvalitativ metod [Interpration and reflection: Philosophy of science and qualitative methods] (2nd ed.). Lund:

Studentlitteratur.

Anderson, D. R. (1987). Creativity and the philosophy of C.S. Pierce. Dordrecht: Martinus Nijhoff.

Atkinson, P., Coffey, A., \& Delamont, S. (2003). Key themes in qualitative research. Walnut Creek, CA: AltaMira Press.

Blumer, H. (1969). Symbolic interactionism. Berkeley: University of California Press.

Bowen, G. A. (2006). Grounded theory and sensitizing concepts. International Journal of Qualitative Methods, 5, 12-23.

Bruce, C. (2007). Questions arising about emergence, data collection, and its interaction with analysis in a grounded theory study. International Journal of Qualitative Methods, 6, 51-68.

Bryant, A. (2002). Re-grounding grounded theory. Journal of Information Technology Theory and Application, 4, 25-42.

Bryant, A. (2009). Grounded theory and pragmatism: The curious case of Anselm Strauss. Forum: Qualitative Social Research, 10(3), Art. 2. Retrieved July 4, 2011, from http://www.qualitativeresearch.net/index.php/fqs/article/viewArticle/1358/2850

Bryant, A., \& Charmaz, K. (2007). Grounded theory in historical perspective: An epistemological account. In A. Bryant \& K. Charmaz (Eds.), The SAGE Handbook of Grounded Theory (pp. 31-57). Los Angeles: Sage.

Burton, R. (2007). The Anatomy of Melancholy (Vol. 1). Teddington: Echo Library, [Original edition, 1638].

Carson, D. (2009). The abduction of Sherlock Holmes. International Journal of Police Science \& Management, 11, 193-202.

Chalmers, A. F. (1999). What is this thing called science? (3rd ed.). New York: Open University Press.

Charmaz, K. (1995). Between positivism and postmodernism: Implications for methods. Studies in Symbolic Interaction, 17, 43-72.

Charmaz, K. (2000). Grounded theory: Objectivist and constructivist methods. In N. K. Denzin \& Y. S. Lincoln (Eds.), Handbook of qualitative research (2nd ed., pp. 509-535). Thousand Oaks, CA: Sage. 
Charmaz, K. (2006). Constructing grounded theory. London: Sage.

Charmaz, K. (2008). Constructionism and the grounded theory method. In J. A. Holstein \& J. F. Gubrium (Eds.), Handbook of constructionist research (pp. 397-412). New York: The Guilford Press.

Charmaz, K. (2009). Shifting the grounds: Constructivist grounded theory methods. In J. M. Morse, P. N. Stern, J. Corbin, B. Bowers, K. Charmaz, \& A. E. Clarke (Eds.), Developing grounded theory: The second generation (pp. 127-154). Walnut Creek: Left Coast Press.

Cherubini, L., Niemczyk, E., Hodson, J., \& McGean, S. (2010). A grounded theory of new Aboriginal teachers' perceptions: The cultural attributions of medicine wheel teachings. Teachers and Teaching: Theory and Practice, 16, 545-557.

Clarke, A.E. (2005). Situational analysis: Grounded theory after the postmodern turn. Thousand Oaks: Sage.

Dey, I. (1993). Qualitative data analysis. London: Routledge.

Dey, I. (1999). Grounding grounded theory. San Diego: Academic Press.

Dey, I. (2004). Grounded theory. In C. Seale, G. Gobo, J. F. Gubrium, \& D. Silverman (Eds.), Qualitative research practice (pp. 80-93). London: Sage.

Dey, I. (2007). Grounding categories. In A. Bryant \& K. Charmaz (Eds.), The SAGE handbook of grounded theory (pp. 167-190). Los Angeles: Sage.

Douven, I. (2011a). Abduction. In E. N. Zalta (Principal Ed.), Stanford encyclopedia of philosophy. Retrieved July 4, 2011, from http://plato.stanford.edu/entries/abduction/

Douven, I. (2011b). Pierce on abduction. In E. N. Zalta (Principal Ed.), Stanford encyclopedia of philosophy. Retrieved July 4, 2011, http://plato.stanford.edu/entries/abduction/

Drugli, M. B., Clifford, G., \& Larsson, B. (2008). Teachers' experience and management of young children treated because of home conduct problems: A qualitative study. Scandinavian Journal of Educational Research, 52, 279-291.

Dunne, C. (2011). The place of literature review in grounded theory research. International Journal of Social Research Methodology, 14, 111-124.

Givon, S., \& Court, D. (2010). Coping strategies of high school students with learning disabilities: A longitudinal qualitative study and grounded theory. International Journal of Qualitative Studies in Education, 23, 283-303.

Glaser, B. G. (1978). Theoretical sensitivity. Mill Valley, CA: Sociology Press.

Glaser, B. G. (1992). Basics of grounded theory analysis. Mill Valley, CA: Sociology Press.

Glaser, B. G. (1998). Doing grounded theory: Issues and discussions. Mill Valley, CA: Sociology Press.

Glaser, B. G. (2001). The grounded theory perspective I: Conceptualization contrasted with description. Mill Valley, CA: Sociology Press. 
Glaser, B. G. (2004). Remodeling grounded theory. Forum: Qualitative Social Research, 5(2), Art. 4. Retrieved July 4, 2011, from http://www.qualitative-

research.net/index.php/fqs/article/viewArticle/607/1315

Glaser, B. G. (2005). The grounded theory perspective III: Theoretical coding. Mill Valley, CA: Sociology Press.

Glaser, B. G. (2007). Doing formal grounded theory: A proposal. Mill Valley, CA: Sociology Press.

Glaser, B. G., \& Strauss, A. L. (1967). The discovery of grounded theory. New York: Aldine.

Goldkuhl, G., \& Cronholm, S. (2010). Adding theoretical grounding to grounded theory: Toward multigrounded theory. International Journal of Qualitative Methods, 9, 187-205.

Hallberg, L. R.-M. (2010). Some thoughts about the literature review in grounded theory studies. International Journal of Qualitative Studies in Health Well-Being, 5, 1.

Hammersley, M., \& Atkinson, P. (2007). Ethnography: Principles in practice (3rd). London: Routledge.

Hanson, N.R. (1965). Patterns of discovery: An inquiry into the conceptual foundations of science. Cambridge: Cambridge University Press.

Heath, H. (2006). Exploring the influences and use of the literature during a grounded theory study. Journal of Research in Nursing, 11, 519-528.

Henwood, K., \& Pidgeon, N. (2003). Grounded theory in psychological research. In P. M. Camic, J. E. Rhodes, \& L. Yardley (Eds.), Qualitative research in psychology: Expanding perspectives in methodology and design (pp. 131 - 155). Washington, DC: American Psychological Association.

Hickey, G. (1997). The use of literature in grounded theory. Nursing Times Research, 2, 371-378.

Holton, J. A. (2007). The coding process and its challenges. In A. Bryant \& K. Charmaz (Eds.), The SAGE handbook of grounded theory (pp. 265-289). Los Angeles: Sage.

Kelle, U. (1995). Theories as heuristic tools in qualitative research. In I. Maso, P. A. Atkinson, S. Delamont, \& J. C. Verhoeven (Eds.), Openness in research: The tension between self and other (pp. 3350). Assen: van Gorcum.

Kelle, U. (2005). "Emergence" vs. "forcing" of empirical data? A crucial problem of "grounded theory" reconsidered. Forum: Qualitative Social Research, 6(2), Art. 27. Retrieved July 4, 2011, from http://www.qualitative-research.net/index.php/fqs/article/viewArticle/467/1000

Kelle, U. (2007). The development of categories: Different approaches in grounded theory. In A. Bryant \& K. Charmaz (Eds.), The SAGE handbook of grounded theory (pp. 191-213). Los Angeles: Sage.

Leino, K. (2006). Reading the web - students' perceptions about the Internet. Scandinavian Journal of Educational Research, 50, 541-557.

Lempert, L. B. (2007). Asking questions of the data: Memo writing in the grounded theory tradition. In A. Bryant \& K. Charmaz (Eds.), The SAGE handbook of grounded theory (pp. 245-264). Los Angeles: Sage. 
Lind, M., \& Goldkuhl, G. (2006). How to develop a multi-grounded theory: The evolution of a business process theory. Australasian Journal of Information Systems, 13, 69-85.

Locke, K. (2007). Rational control and irrational free-play: Dual-thinking modes as necessary tension in grounding theorizing. In A. Bryant \& K. Charmaz (Eds.), The SAGE handbook of grounded theory (pp. 565-579). Los Angeles: Sage.

Martin, V. B. (2006). The relationship between an emerging grounded theory and the existing literature: Four phases for consideration. Grounded Theory Review, 5, 47-50.

McCallin, A. M. (2006). Grappling with the literature in a grounded theory study. Grounded Theory Review, 5, 11-27.

McGhee, G., Marland, G. R., \& Atkinson, J. (2007). Grounded theory research: Literature reviewing and reflexivity. Journal of Advanced Nursing, 60, 334-342.

Mills, J., Bonner, A., \& Francis, K. (2006a). Adopting a constructivist approach to grounded theory: Implications for research design. International Journal of Nursing Practice, 12, 8-13.

Mills, J., Bonner, A., \& Francis, K. (2006b). The development of constructivist grounded theory. International Journal of Qualitative Methods, 5, 25-35.

Montgomery, P., \& Bailey, P. H. (2007). Field notes and theoretical memos in grounded theory. Western Journal of Nursing Research, 29, 65-79.

Morse, J. M. (1994). "Emerging from the data": The cognitive processes of analysis in qualitative inquiry. In J.M. Morse (Ed.), Critical issues in qualitative research methods (pp. 23-43). Thousand Oaks: Sage.

Morse, J. M. (2001). Situating grounded theory within qualitative inquiry. In R. S. Schreiber \& P. N. Stern (Eds.), Using grounded theory in nursing (pp. 1-15). New York: Springer Publishing Company.

Mruck, M., \& Mey, G. (2007). Grounded theory and reflexivity. In A. Bryant \& K. Charmaz (Eds.), The SAGE handbook of grounded theory (pp. 515-538). Los Angeles: Sage.

Olesen, V. L. (2007). Feminist qualitative research and grounded theory: Complexities, criticisms, and opportunities. In A. Bryant \& K. Charmaz (Eds.), The SAGE handbook of grounded theory (pp. 417-435). Los Angeles: Sage.

Patton, M.Q. (2002). Qualitative research \& evaluation methods (3rd ed.). Thousand Oaks: Sage.

Pierce, C.S. (1958). Collected papers of Charles Sanders Pierce. Vol. VII: Science and philosophy. Cambridge: Harvard University Press. [Edited by A. W. Burks].

Reichertz, J. (2010). Abduction: The logic of discovery of grounded theory. Forum: Qualitative Social Research, 11(1), Art. 13. Retrieved July 4, 2011, from http://www.qualitativeresearch.net/index.php/fqs/article/viewArticle/1412/2902

Richardson, R., \& Kramer, E.H. (2006). Abduction as the type of inference that characterizes the development of a grounded theory. Qualitative Research, 6, 497-513.

Rorty, R. (1979). Philosophy and the mirror of nature. Princeton, NJ: Princeton University Press. 
Rorty, R. (1998). Truth and progress: Philosophical papers (Vol. 3). Cambridge: Cambridge University Press.

Schreiber, R. S. (2001). The "how to" of grounded theory: Avoiding the pitfalls. In R. S. Schreiber \& P. N. Stern (Eds.), Using grounded theory in nursing (pp. 55-83). New York: Springer Publishing Company.

Schurz, G. (2008). Patterns of abduction. Synthese, 164, 201-234.

Silverman, D. (2000). Doing qualitative research (2nd ed.). London: Sage.

Smart, J. B., \& Brent, I. L. (2010). A grounded theory of behavior management strategy selection, implementation, and perceived effectiveness reported by first-year elementary teachers. Elementary School Journal, 110, 567-584.

Stern, P. N. (2007). On solid ground: Essential properties for growing grounded theory. In A. Bryant \& K. Charmaz (Eds.), The SAGE handbook of grounded theory (pp. 114 - 126). Los Angeles: Sage.

Strauss, A., \& Corbin, J. (1990). Basics of qualitative research. Newbury Park: Sage.

Strauss, A. L., \& Corbin, J. M. (1994). Grounded theory methodology: An overview. In N. K. Denzin \& Y. S. Lincoln (Eds.), Handbook of qualitative research (pp. 273-285). London: Sage.

Strauss, A., \& Corbin, J. (1998). Basics of qualitative research (2nd ed.). Thousand Oaks: Sage.

Suddaby, R. (2006). What grounded theory is not. Academy of Management Journal, 49, 633-642.

Thayer-Bacon, B. J. (1996). An examination and redescription of epistemology, Retrieved December 5, 2008, from ERIC website: http://www.eric.ed.gov:80/ERICWebPortal/custom/portlets/ recordDetails/detailmini.jsp?_nfpb=true\&_\&ERICExtSearch_SearchValue_0=ED401279\&ERIC ExtSearch_SearchType_0=no\&accno=ED401279.

Thayer-Bacon, B. J. (2003). Pragmatism and feminism as qualified relativism. Studies in Philosophy and Education, 22, 417-438.

Thomas, G., \& James, D. (2006). Reinventing grounded theory: Some questions about theory, ground and discovery. British Educational Research Journal, 32, 767-795.

Thornberg, R., \& Charmaz, K. (in press). Grounded theory. In S.D. Lapan, M. Quartaroli, \& F. Reimer (Eds.), Qualitative research: An introduction to methods and designs. San Francisco: Jossey- Bass.

Timmermans, S., \& Tavory, I. (2007). Advancing ethnographic research through grounded theory practice. In A. Bryant \& K. Charmaz (Eds.), The SAGE handbook of grounded theory (pp. 493-512). Los Angeles: Sage.

Truzzi, M. (1976). Selective attention: Sherlock Holmes: Applied social psychologist. In W.B. Sanders (Ed.), The sociologist as detective (2nd ed., pp. 50-86). New York: Praeger.

Urquhart, C. (2007). The evolving nature of grounded theory method: The case of the information systems discipline. In A. Bryant \& K. Charmaz (Eds.), The SAGE handbook of grounded theory (pp. 339-360). Los Angeles: Sage. 